\title{
MATHEMATICAL SIMULATION OF POLLUTANT SPREAD IN RIVERS: A CASE STUDY OF FECAL COLIFORMS IN THE CHILI RIVER OF AREQUIPA, PERU
}

\author{
ANDRES V. PEREZ ${ }^{*}$, ANAI PEREZ MANRIQUE ${ }^{1} \&$ NATALY PEREZ MANRIQUE ${ }^{2}$ \\ ${ }^{1}$ Department of Civil Engineering and Architecture, National University of Saint Agustin, Peru \\ ${ }^{2}$ Department of Civil \& Environmental Engineering, Duke University, USA
}

\begin{abstract}
The process of river pollution arises when many cities allow untreated wastewater to flow directly into rivers and other bodies of water. This process generates a lot of pollution, especially in the form of fecal coliforms, which damage the health of the people who depend on the river, as well as the river ecosystem itself. This research design investigates the specific case of the Chili River in Arequipa, Peru. The concentration of pollutants, fecal coliforms in water flow in particular, is represented with a mathematical model expressed with differential equations which contain the components of diffusion, convection, reaction or decay, and source. These equations cannot be solved analytically, so, for this reason, the finite element and Petrov-Galerkin methods have been used due to the predominant component being convection. The Chili River passes through the city of Arequipa, which has a population of about one million people. The city's wastewater is dumped directly into this river without first being treated, with an approximate flow of $1.2 \mathrm{~m}^{3} / \mathrm{s}$. The simulation was conducted utilizing a 30 kilometer stretch of the river. For boundary conditions and simulation calibration, water samples were taken from the river at different points and analyzed in the laboratory in order to determine the concentration values of fecal coliforms. The river was divided into several sections to simulate the concentration of fecal coliforms. The results obtained after the calibration were very alarming, since the concentration of fecal coliforms in some sections reached values of up to 20,005,397.68 PMN/100 $\mathrm{ml}(\mathrm{PMN}=$ probable maximum number). These values are "well above" the maximum permissible limit (MPL $=10,000 \mathrm{PMN} / 100 \mathrm{ml})$ and standard environmental quality $(\mathrm{SEQ}=1,000 \mathrm{PMN} / 100 \mathrm{ml})$. Only in the sections of the Chili River upstream of the city was the water quality acceptable.

Keywords: simulation of pollutants in rivers, finite element method, Petrov-Galerkin, fecal coliforms.
\end{abstract}

\section{INTRODUCTION}

River pollution is one of the most critical problems in many of our cities that discharge, without treatment, untreated wastewater from drains directly into the river, and this wastewater unfortunately flows into the sea. The Chili River of Arequipa is highly contaminated by the emission of industrial and domestic waste into its waters. These wastes are dumped directly into an approximately 30 kilometer stretch of the river. In this section there are about fifty points of discharge of domestic wastewater, with a total of $1.2 \mathrm{~m}^{3} / \mathrm{s}$. being the average flow of the river of $7.5 \mathrm{~m}^{3} / \mathrm{s}[1]$.

Around 17,000 hectares of farmland are irrigated with this polluted river water. On the other hand, the Chili River is the climatic "main regulator" of the city of Arequipa. This is to say that the climate of the city is extremely arid, and it is exposed to high levels of solar radiation. However, these two factors are in part mitigated by the Chili River, which provides a reliable source of water for the city and its inhabitants. If excessive pollution of the river continues, this will usher in the beginning of the inhabitability of the city of Arequipa.

This research establishes the governing equations of the pollutant-transport process in rivers. The equation is solved with the finite-element method (FEM); due to the phenomenon

*ORCID: http://orcid.org/0000-0002-3404-4349 


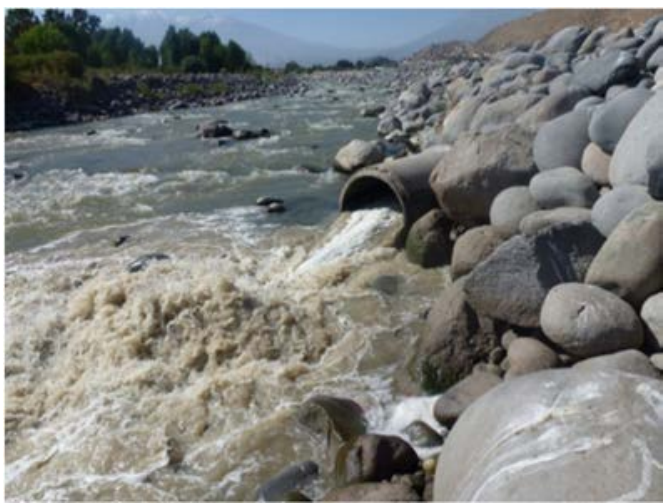

Figure 1: Alata dump site view. Direct discharge from the drain into the Chili River with a flow of $930 \mathrm{l} / \mathrm{s}$.

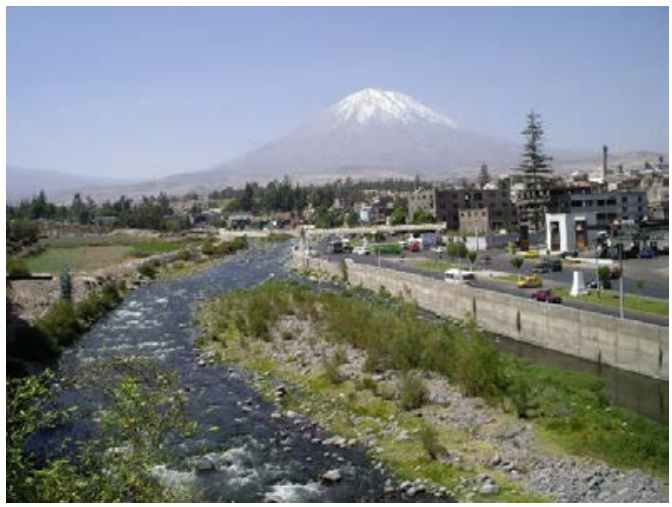

Figure 2: View of the Chili River crossing the city of Arequipa at the foot of volcano Misti.

being convention dominant, the Petrov-Galerkin method is utilized. The simulation is performed in order to calculate the quantitative concentration of fecal coliforms in the Chili River. Previous to the mathematical analysis, field work was carried out in order to obtain information regarding the boundary conditions of the computer simulation, for example, velocity, river flow, monitoring of fecal coliforms, as well as sewage effluents at different points along the river.

\section{GOVERNING EQUATIONS}

Pollution is defined as the action of introducing materials or forms of energy into water directly or indirectly, which implies a harmful alteration of its quality in relation to subsequent uses or its ecological function [2]. This physical phenomenon is represented by a mathematical model, expressed in the form of a differential equation, called the pollutanttransport model, which consists of four components: diffusion, convection, source, and firstorder reactions or decay.

a) Diffusion is the net transport of the pollutant due to its random movement within the flow of water or air, due to the difference or concentration gradient. 
b) Convection is when the mass of fluid moves and the pollutant is transported inside it.

c) Decay or first-order reaction within the water, producing chemical reactions due to the presence of the contaminant, is defined as $\mathrm{R}=-\mathrm{DC}$.

d) Source is the way to externally introduce a volume of contaminant directly into the water flow.

The definitions described above are idealized in Fig. 3 [3], which is a differential cube represented by the four components, according to the rules of the laws of derivatives, in order to then apply the law of conservation of the mass of the fluid and pollutant.

In Fig. 3, $C$ is the concentration of contaminant (fecal coliforms, PMN/100 mg); $u, v, w$ represent the water-flow velocity $(\mathrm{m} / \mathrm{s})$ in the directions $x, y, z ; k$ is the diffusion coefficient $\left(\mathrm{m}^{2} / \mathrm{s}\right) ; D$ is decay coefficient (1/s) [4]; and $S$ is the source term (PMN). Applying the law of conservation of the mass, inside the differential cube of Fig. 3, it is necessary that the variation of the mass of the pollutant per unit of time inside the differential cube be equal to the speed of the mass that enters the volume on the left side, minus the mass that comes out from the right side, adding to this the mass of contaminant that wins out because of $S$ (source), minus DC (decay). After a long process of mathematical operations utilizing differential calculus, the governing equation for the transport of pollutants is obtained [3]. For the twodimensional case, the following equation is rendered:

$$
\frac{\partial C}{\partial t}=-u \frac{\partial C}{\partial x}-v \frac{\partial C}{\partial y}-\frac{\partial}{\partial x}\left(k_{x} \frac{\partial C}{\partial x}\right)+\frac{\partial}{\partial y}\left(k_{y} \frac{\partial C}{\partial y}\right)+S-D C .
$$

Eqn (1) cannot be solved analytically by the conventional methods of integral calculus, and this fact makes it necessary to provide numerical solutions. In this research the finiteelement method has been used, as well as the Petrov-Galerkin method because it is a convection-dominant problem.

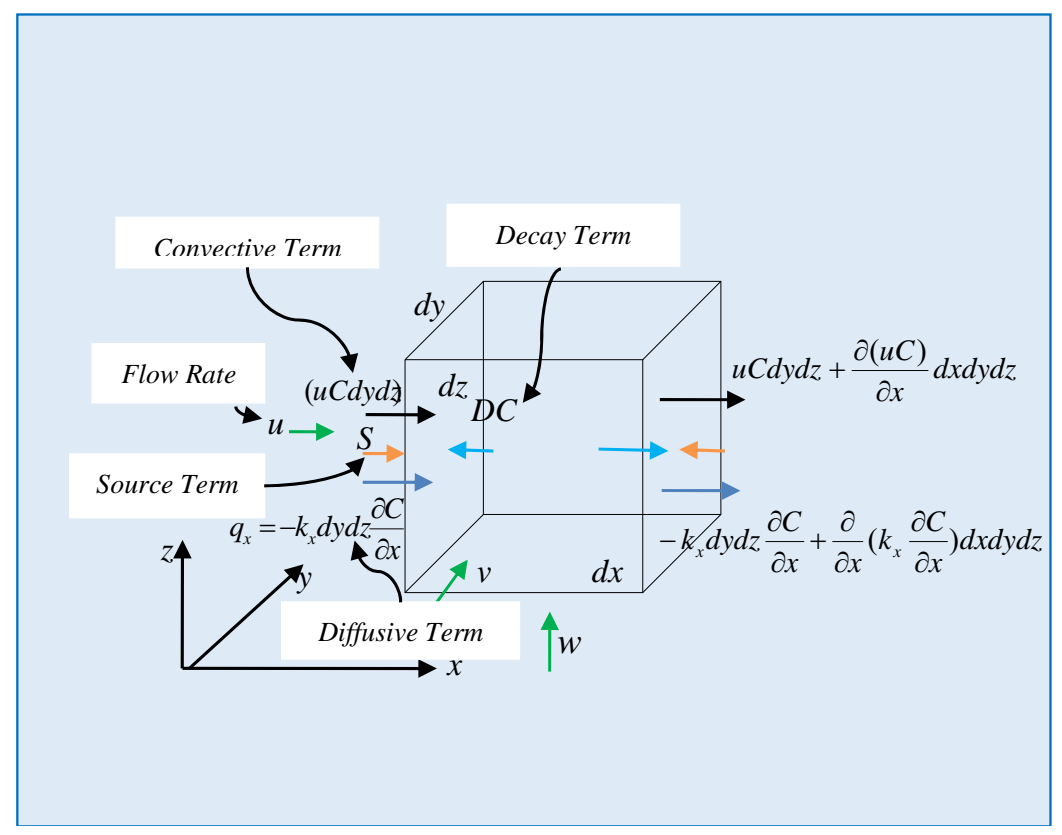

Figure 3: Mathematical schematization of the transport model pollutants by convection, diffusion, and others. 


\section{METHODOLOGY SOLUTION}

The governing equations are solved and then applied, simulating the concentration of fecal coliforms for the case of the Chili River in Arequipa, Peru.

\subsection{Finite element method}

The governing equations cannot be solved with traditional analytical methods; therefore, the finite-element method is used. This method consists of transforming the differential equations into integral equations and then later into matrices and vectors, which are subsequently solved with linear algebra.

\subsubsection{Petrov-Galerkin method}

In order to perform the above-described transformations, there are several methods, such as the direct method, variational method, and weighted-residual method, and within this method is the sub-domain method, placement method, least-squares method, Galerkin method, and Petrov-Galerkin method [5]. This last method is the one that will be used in this research project because it is the only one which adequately solves governing equations which have a convective component; the other methods would fail.

The Petrov-Galerkin method consists of defining the "weight" or "weighing" with the following expression [5].

$$
W_{i}=N_{i}+N^{\prime}{ }_{i}
$$

with $i=1,2 N_{i}$ being the weight of the Galerkin method, which can also be defined as:

$$
N^{\prime}{ }_{i}=\alpha \frac{h_{i}}{2}\left(\frac{\partial N_{i}}{\partial x}\right),
$$

where, $x_{2}-x_{1}=h_{1}=h_{i}$, for an element

$$
|\alpha|=\alpha_{o p t}=\operatorname{Coth}|\boldsymbol{P e}|-\frac{1}{\boldsymbol{P e}},
$$

with $\alpha_{\text {opt }}=\alpha$ being a countercurrent parameter for convective terms. Pe is Peclet's number, which is expressed as:

$$
\boldsymbol{P} \boldsymbol{e}=\frac{u h_{i}}{2 k}
$$

Replacing eqn (3) in eqn (2) yields:

$$
W_{i}=N_{i}+\alpha \frac{h_{i}}{2}\left(\frac{\partial N_{i}}{\partial x}\right) .
$$

On the other hand, to eqn (1), which we call $R$, we multiply the weighting eqn (2), which yields a result of zero:

$$
\int W_{i} R d x=0 .
$$

After a long mathematical process of differential and integral calculus and the application of some mathematical theorems, the eqn (7) is transformed into integral equations and later into a "system of matrices and vectors" for each element (section). For considerations of space in this research, the details of these operational processes are not described [3]. The results of these transformations are given below for each term of the governing equation:

$$
u \frac{\partial C}{\partial x}=\frac{u}{2}\left[\begin{array}{ll}
-1+\alpha & 1-\alpha \\
-1-\alpha & 1+\alpha
\end{array}\right]\left\{\begin{array}{l}
C_{1} \\
C_{2}
\end{array}\right\} .
$$


This "solution" matrix of the differential equation of the "convective" part, we note that the differential equation has become a square matrix called the "convection stiffness matrix" $\left(k_{c}\right)$.

Below is the solution to the term "diffusive":

$$
-k_{x} \frac{\partial}{\partial x}\left(\frac{\partial C}{\partial x}\right)=\frac{k_{x}}{h}\left[\begin{array}{cc}
1 & -1 \\
-1 & 1
\end{array}\right]\left\{\begin{array}{l}
C_{1} \\
C_{2}
\end{array}\right\}+k_{x}\left\{\begin{array}{c}
\frac{\partial C\left(x_{1}\right)}{\partial x} \\
-\frac{\partial C\left(x_{2}\right)}{\partial x}
\end{array}\right\}+\frac{\alpha k_{x}}{2}\left\{\begin{array}{c}
\frac{\partial C\left(x_{2}\right)}{\partial x}-\frac{\partial C\left(x_{1}\right)}{\partial x} \\
-\frac{\partial C\left(x_{2}\right)}{\partial x}+\frac{\partial C\left(x_{1}\right)}{\partial x}
\end{array}\right\}
$$

The result is a matrix and two vectors; the vectors in derivatives are known as natural boundary conditions. It is called a "diffusion stiffness matrix" $\left(k_{d}\right)$. Below is the "decay" term called the decay matrix $\left(\mathrm{k}_{\mathrm{dec}}\right)$ :

$$
D C=\frac{D h}{2}\left[\begin{array}{cc}
\frac{2}{3}-\frac{\alpha}{2} & +\frac{2}{6}-\frac{\alpha}{2} \\
\frac{2}{6}+\frac{\alpha}{2} & \frac{2}{3}+\frac{\alpha}{2}
\end{array}\right]\left\{\begin{array}{l}
C_{1} \\
C_{2}
\end{array}\right\}
$$

The solution of the "source" term, a source vector being the solution $\left(\mathrm{k}_{\mathrm{fue}}\right)$ :

$$
S=\frac{S h}{2}\left\{\begin{array}{l}
-1+\alpha \\
-1-\alpha
\end{array}\right\}
$$

Finally, the solution of the governing eqn (1) is the sum of eqns (8)-(11) for "an element". The complete solution is the sum of all the elements in which the domain of the problem has been discretized.

\subsection{Simulation calculation procedure}

Replacing the known data and parameters in the matrix eqns (8)-(11), we obtain the first concentration values of fecal coliforms in the Chili River. The procedure is as follows:

a) The matrices and vectors called "local" are obtained. It consists of replacing the data for each element in which the domain of the problem has been discretized. Detailed matrix operations are not presented in this investigation due to space issues [3]. Algebraically, it adds the convection-stiffness matrix $k_{c}$, the diffusion-stiffness matrix $k_{d}$, the decay-stiffness matrix $k_{d e c}$, and the stiffness-matrix source $k_{f u e}$ to each element. The total sum is called the "local matrix of an element" $k_{i}$. The sum is $k_{c}+k_{d}+k_{d e c}+k_{f u e}=k_{i}$, being the local vectors $f$. This process is done for the twenty-eight elements in which the domain has been discretized.

b) The twenty-eight matrices and local vectors are assembled in a single matrix called the "global matrix" $\mathrm{K}$ ' and "global vector" $\mathrm{F}$ '.

c) The boundary conditions are applied to the matrix and global vector, with which a "new global matrix" K and a new global vector $\mathrm{F}$ are obtained.

d) These new matrices and global vectors were solved with linear algebra, using the Gauss-Seidel method [6] or another method, as follows: $\{\mathrm{C}\}=[\mathrm{K}]^{-1}\{\mathrm{~F}\}$ with $\{\mathrm{C}\}$ being the vector result of the fecal coliform concentration and the inverse of the new global matrix.

e) Subsequently the calibration of the model is performed.

f) After the calibration it is possible to simulate new hypothetical scenarios of the concentration phenomenon of fecal coliforms in the Chili River.

The complete procedure for a real application involves a lot of mathematical operations; in this case it was done with our own software. 


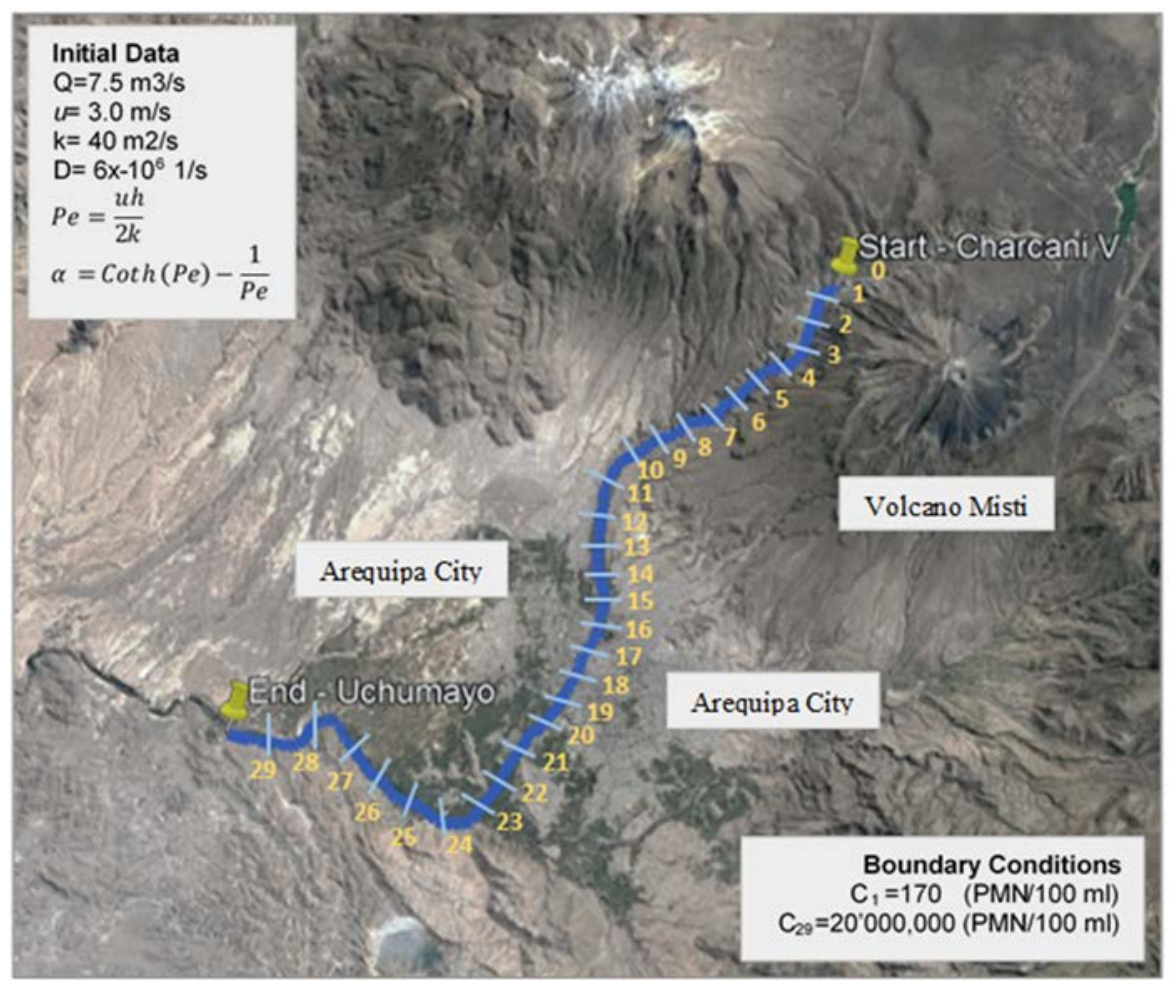

Figure 4: Scheme (discretization) in sections of the Chili River for simulation.

\section{RESULTS OF THE SIMULATION OF THE CHILI RIVER: CALIBRATION}

\subsection{Simulation of the Chili River}

The premise on which the simulation models are based lies in assuming the fact that if a certain model is "capable of reproducing preterit situations" of a system or physical phenomenon whose parameters, (i.e., input data and external actions) are known, presumably, it will be able to predict "future situations", allowing us to "anticipate in time" the evolution of the system and take the appropriate precautionary or corrective measures to guarantee the evolution of that system within acceptable environmental limits. In this case it is applied to the Chili River.

\subsection{Calibration}

The most important phase of the simulation of the model consists of making dozens or even hundreds of computational simulations (runs) of the model, "varying" in each of the runs the "parameters" of departure, and then "comparing" the results produced by the simulated model with those measured in the field or laboratory, until a good "coincidence" between both results is obtained.

Some of the calibration parameters available have a high credibility for their origin or form of determination, while others have less credibility. Some of them are even estimated from different sources (e.g. bibliography, previous or similar studies, etc.). In this research, 
the calibration parameters used were the diffusion and decay coefficients, the values of which were initially taken from previous studies conducted in the area.

One part of the "measured" values of fecal coliforms C (PMN/100 ml) were obtained from analysis in specialized laboratories of the university while the other part was provided by the company charged with drinking water and sewerage in Arequipa called SEDAPAR. The calibration ended when the "difference" between the simulated results and the measured data coincided within a certain margin of acceptable error (see Table 1).

\subsection{Results}

Once the respective matrix operations of the simulation process have been performed, the results of fecal-coliform concentrations in the Chili River are shown in Table 2 and Figs 57; $\mathrm{U}$ being velocity of river flow; $h$ the length of the section; $k$ the diffusion coefficient; Pe the Peclet number, which is dimensionless; Coth the hyperbolic cotangent of Peclet; $\alpha$ (alpha) the coefficient of countercurrent of the convective term; D the coefficient of decay; and C the concentration of fecal coliforms. The entire calculation process was carried out with our own software and Excel spreadsheet; no commercial software was used.

Generation of another scenario, when the Chili River increases its flow to $75 \mathrm{~m}^{3} / \mathrm{s}$ in the summer season (January and February) due to the high rainfall in the collection basin.

\section{CONCLUSIONS AND DISCUSSION}

From the results of this research, it is concluded that for the first 22 kilometers of the Chili River, from Charcani V (C1) to the Grau Bridge (C16) the average of the simulated values is $172 \mathrm{PMN} / 100 \mathrm{ml}$, which is below the standard of environmental quality (SEQ $=1,000$ $\mathrm{PMN} / 100 \mathrm{ml}$ ) and below the maximum permissible limits $(\mathrm{MPL}=10,000 \mathrm{MPN} / 100 \mathrm{ml})$ for natural rivers.

From Grau Bridge (C16) to section C22, a section of more than 7 kilometers, the simulated values have an average of 3,540 PMN/100 $\mathrm{ml}$. This value exceeds the SEQ; however, they are below the maximum permissible limits for natural rivers.

From section C23 the Chili River is "contaminated" with fecal coliforms. Nevertheless, it is from Sector Alta C24 where the contamination is "alarming" since the concentration values are higher than $20,000,000 \mathrm{PMN} / 100 \mathrm{ml}$. This value is approximately 2,000 times higher than the MPL. Consequently, these waters are not suitable for irrigation or animal consumption, and even less for the river ecosystem.

Currently, construction of the sewage treatment plant called Enlozada is being carried out, where most of the drainage of the city of Arequipa will be treated before being introduced into the river.

The finite-element method (FEM) has adequately simulated the fecal-coliform transport process, since the values simulated with the model have very good agreement with the values measured in the laboratory.

The usefulness of computational simulations lies in the fact that we can generate several model scenarios, which would be impossible in concrete situations.

Table 1: Concentration of fecal coliforms (PMN/100 ml) after calibration between measured and simulated data.

\begin{tabular}{|l|c|c|c|c|c|}
\hline Section & C-10 & C-17 & C-20 & C-26 & C-28 \\
\hline Measured & 130.00 & $3,500.00$ & $3,300.00$ & $20,000,000.00$ & $20,000,000.00$ \\
\hline Simulated & 174.28 & $3,505.00$ & $3,529.74$ & $20,005,397.68$ & $20,014,318.22$ \\
\hline
\end{tabular}


Table 2: Summary of numerical results of the simulation process.

\begin{tabular}{|c|c|c|c|c|c|c|c|c|}
\hline $\begin{array}{l}\text { No } \\
\text { Sect }\end{array}$ & $\begin{array}{c}\mathrm{U} \\
(\mathrm{vel}) \\
(\mathrm{m} / \mathrm{s}) \\
\end{array}$ & $\begin{array}{c}\mathrm{h} \\
\text { (leng) } \\
(\mathrm{m}) \\
\end{array}$ & $\begin{array}{c}\mathrm{K} \\
\left(\mathrm{m}^{2} / \mathrm{S}\right)\end{array}$ & $\begin{array}{c}\mathrm{Pe} \\
\text { (Peclet) }\end{array}$ & $\begin{array}{l}\text { Coth } \\
(\mathrm{Pe})\end{array}$ & (alpha) & $\begin{array}{c}\mathrm{D} \\
\text { (1/second })\end{array}$ & $\begin{array}{c}\text { Results } \\
\text { Concentra - C } \\
(\mathrm{PMN} / 100 \mathrm{ml})\end{array}$ \\
\hline 1 & 3.10 & 1404 & 38.51 & 56.510 & 1.000 & 0.9823 & 0.0000061 & 170.00 \\
\hline 2 & 3.20 & 1404 & 38.55 & 58.272 & 1.000 & 0.9828 & 0.0000062 & 170.47 \\
\hline 3 & 3.20 & 1404 & 38.56 & 58.257 & 1.000 & 0.9828 & 0.0000061 & 170.94 \\
\hline 4 & 3.30 & 1404 & 38.61 & 60.000 & 1.000 & 0.9833 & 0.0000059 & 171.41 \\
\hline 5 & 3.30 & 1404 & 38.45 & 60.250 & 1.000 & 0.9834 & 0.0000058 & 171.89 \\
\hline 6 & 3.30 & 1404 & 38.80 & 59.706 & 1.000 & 0.9833 & 0.0000064 & 172.36 \\
\hline 7 & 3.40 & 1404 & 39.10 & 61.043 & 1.000 & 0.9836 & 0.0000062 & 172.84 \\
\hline 8 & 3.40 & 1404 & 38.95 & 61.279 & 1.000 & 0.9837 & 0.0000066 & 173.32 \\
\hline 9 & 3.30 & 1404 & 38.50 & 60.171 & 1.000 & 0.9834 & 0.0000065 & 173.80 \\
\hline 10 & 3.30 & 1404 & 38.66 & 59.922 & 1.000 & 0.9833 & 0.0000062 & 174.28 \\
\hline 11 & 3.30 & 1372 & 38.45 & 58.876 & 1.000 & 0.983 & 0.0000067 & 171.70 \\
\hline 12 & 2.80 & 1372 & 40.20 & 47.781 & 1.000 & 0.9791 & 0.0000066 & 169.34 \\
\hline 13 & 2.80 & 1372 & 41.55 & 46.229 & 1.000 & 0.9784 & 0.0000065 & 167.01 \\
\hline 14 & 2.80 & 1372 & 40.20 & 47.781 & 1.000 & 0.9791 & 0.0000066 & 164.73 \\
\hline 15 & 2.80 & 1372 & 40.21 & 47.769 & 1.000 & 0.9791 & 0.0000068 & 161.39 \\
\hline 16 & 2.80 & 1372 & 39.23 & 48.963 & 1.000 & 0.9796 & 0.0000065 & 222.21 \\
\hline 17 & 2.00 & 1343 & 39.50 & 34.000 & 1.000 & 0.9706 & 0.0000063 & $3,500.00$ \\
\hline 18 & 2.80 & 1343 & 38.65 & 48.647 & 1.000 & 0.9794 & 0.0000065 & $3,514.84$ \\
\hline 19 & 2.80 & 1343 & 38.45 & 48.900 & 1.000 & 0.9796 & 0.0000063 & $3,529.74$ \\
\hline 20 & 2.80 & 1343 & 38.95 & 48.272 & 1.000 & 0.9793 & 0.0000065 & $3,544.71$ \\
\hline 21 & 2.75 & 910 & 38.65 & 32.374 & 1.000 & 0.9691 & 0.0000067 & $3,559.73$ \\
\hline 22 & 2.75 & 910 & 38.10 & 32.841 & 1.000 & 0.9696 & 0.0000066 & $3,382.07$ \\
\hline 23 & 2.80 & 40 & 38.44 & 1.457 & 1.115 & 0.4284 & 0.0000061 & $1,108,869.02$ \\
\hline 24 & 2.90 & 55 & 38.65 & 2.063 & 1.033 & 0.5482 & 0.0000062 & $20,000,000.00$ \\
\hline 25 & 2.80 & 67 & 38.34 & 2.447 & 1.015 & 0.6064 & 0.0000064 & $20,002,385.51$ \\
\hline 26 & 2.90 & 199 & 38.23 & 7.548 & 1.000 & 0.8675 & 0.0000061 & $20,005,397.68$ \\
\hline 27 & 2.90 & 199 & 38.20 & 7.554 & 1.000 & 0.8676 & 0.0000062 & $20,013,773.81$ \\
\hline 28 & 2.90 & 14 & 38.10 & 0.533 & 2.051 & 0.1743 & 0.0000062 & $20,014,318.22$ \\
\hline
\end{tabular}




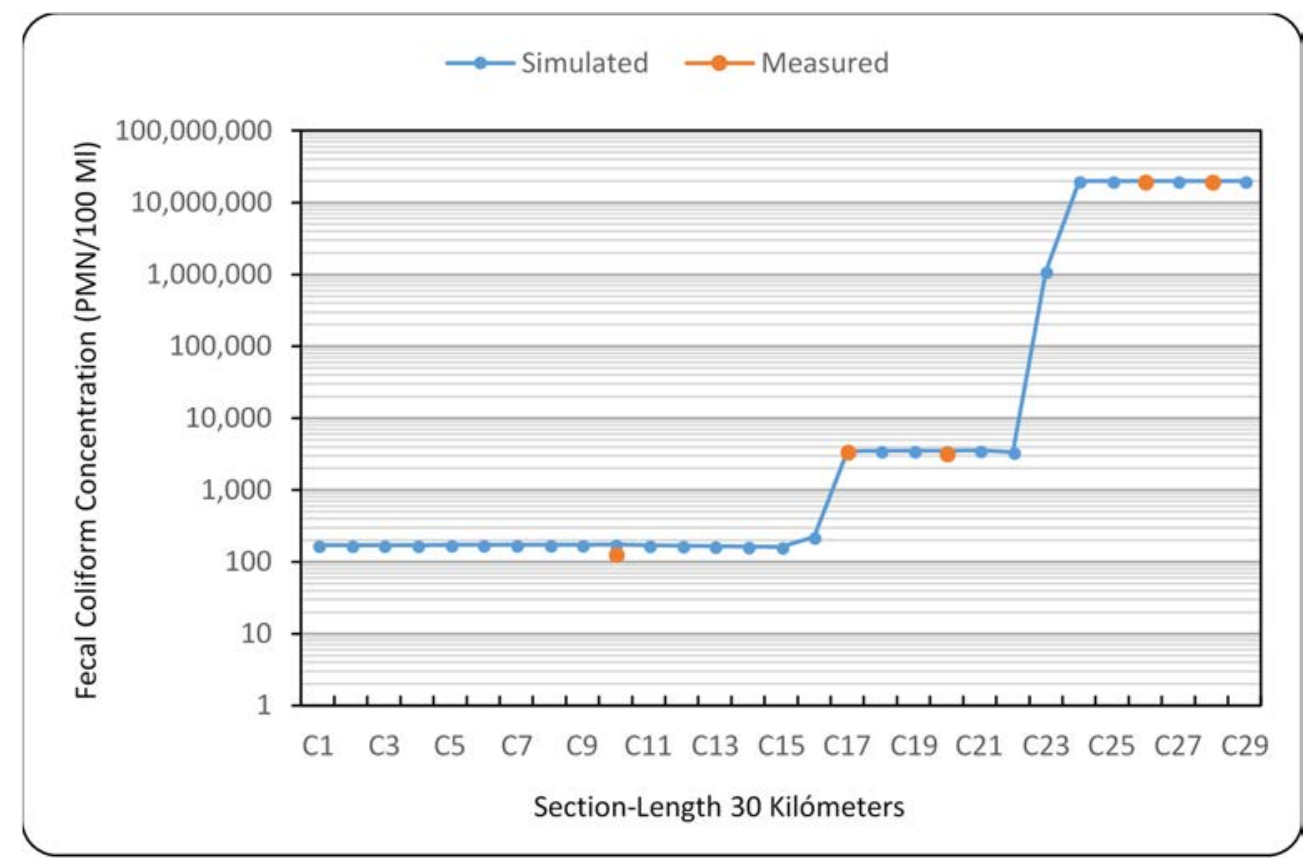

Figure 5: Results of fecal coliform concentration and calibration, flow $7.5 \mathrm{~m}^{3} / \mathrm{s}$.

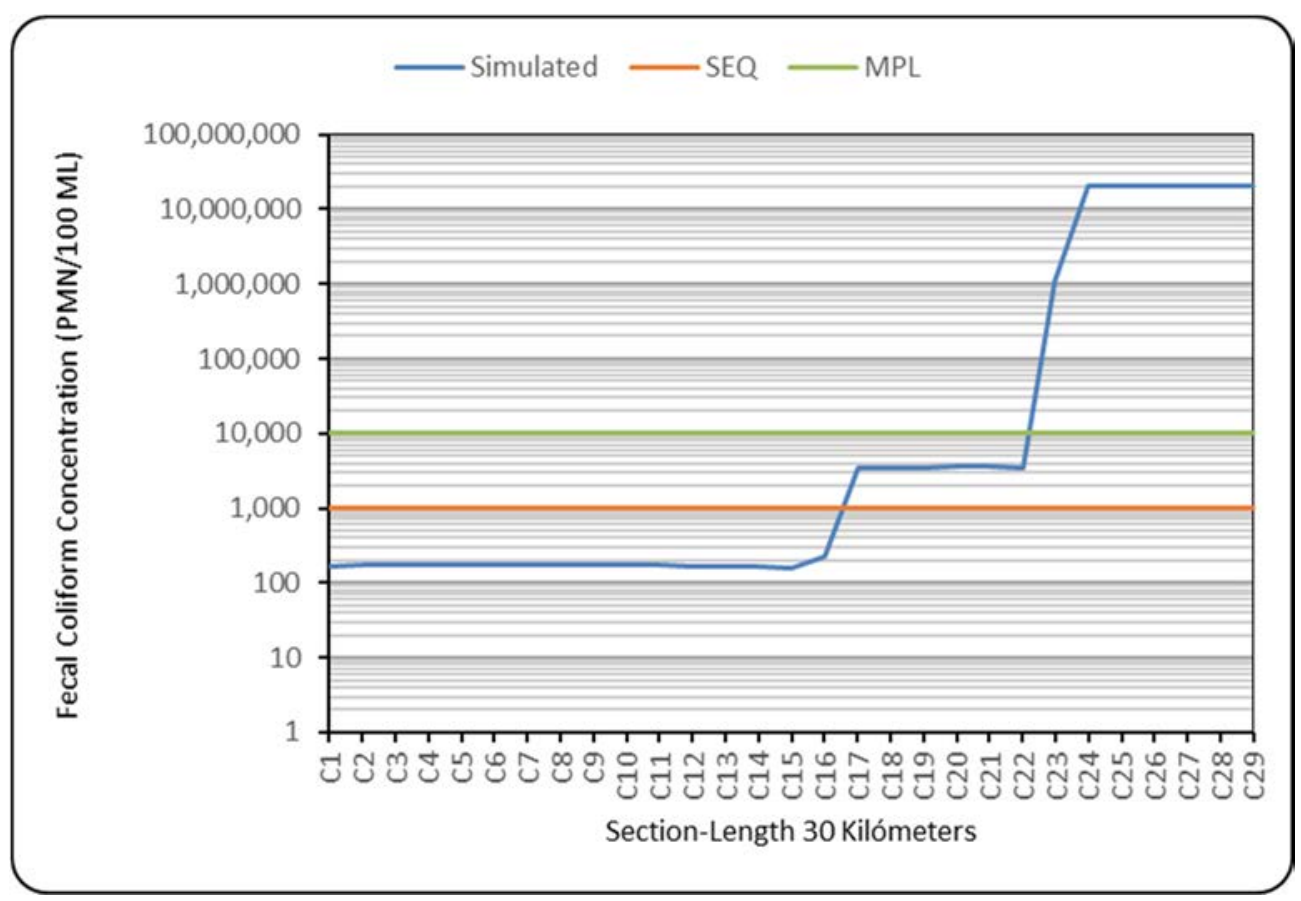

Figure 6: Simulation with flow $7.5 \mathrm{~m}^{3} / \mathrm{s}$; comparison with SEQ and MPL. 


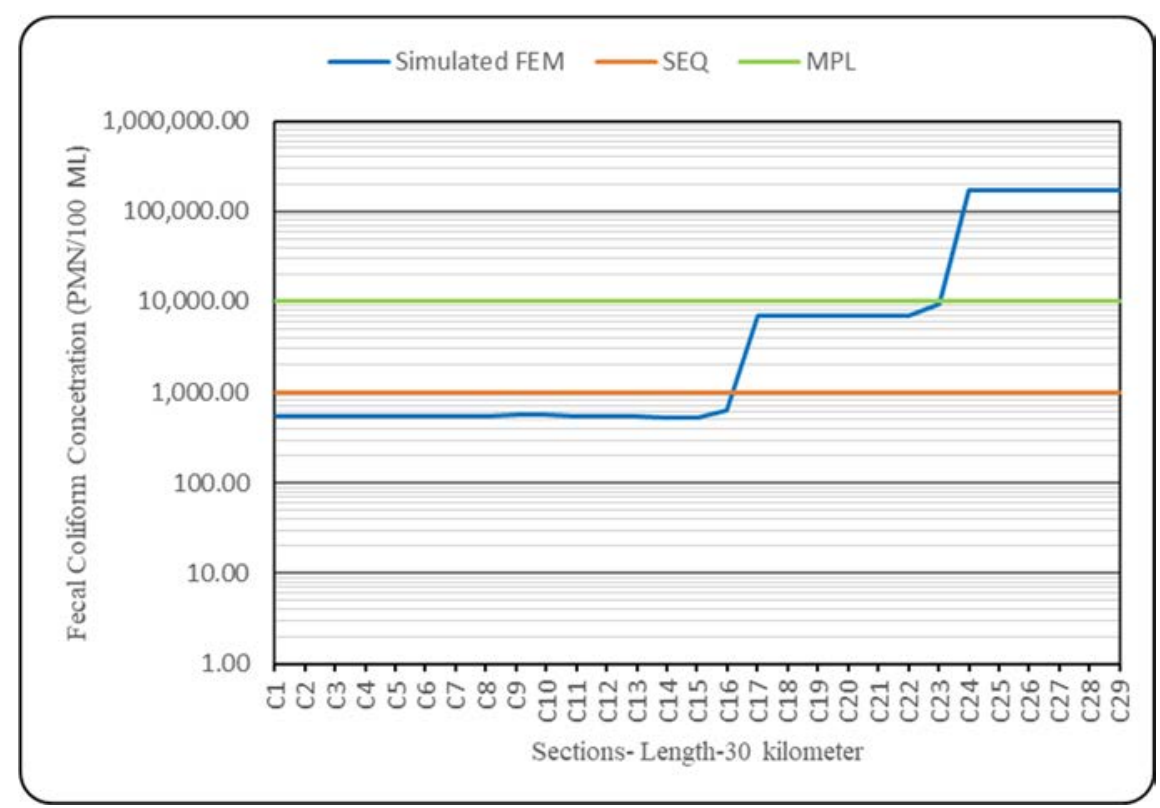

Figure 7: Stage simulation results with flow $75.0 \mathrm{~m}^{3} / \mathrm{s}$ (January) with SEQ and MPL.

In a "real, large" problem of engineering, it is impracticable to monitor/measure values throughout the dimension (spacetime) due to the fact that these values also vary with time (hours, days, months). This problem is adequately overcome with the computational simulations since with this method it is possible to generate several scenarios of large dimensions in space and time, according to the nature of the problem investigated. This is to say that we can generate "fictitious physical phenomena" without actually instantiating them concretely so that we can get the answers that we want for practical applications.

In this case, the Chili River increases its flow to $75 \mathrm{~m}^{3} / \mathrm{s}$ in the months of January and February. This phenomenon was simulated, and as expected the maximum contamination drops to an average value of $170,000.00 \mathrm{PMN} / 100 \mathrm{ml}$, which continues being above the MPL. Currently, projects have been carried out to pump the drainage water to a treatment plant, which would be a part solution for this problem.

\section{REFERENCES}

[1] Perez, A., Proceso de transporte de contaminantes en Arequipa, Universidad Nacional de San Agustin, 2011.

[2] Nepf, H., Transport Processes in the Environment, 2nd ed., McGraw-Hill: New York, 2002.

[3] Perez, A., Simulacion matematica con el metodo de los elementos finitos del proceso de transporte de contaminantes, Universidad Nacional de San Agustin, 2013.

[4] Cardini, J., Zabaletti, A., Oliver, N. \& Mársico, D., Efecto de los Coeficientes de Dispersion Sobre la Modelacion Bidimensional del Transporte de Contaminantes, XXII, Mecanica Computacional: Argentina, 2004.

[5] Zienkiewicz, O.C. \& Taylor, R.L., Solid and Fluid Mechanics: Dynamics and NonLinearity, II, McGraw-Hill: London, 1991.

[6] Kaplan, W., Calculo y Algebra Lineal, 2nd ed., Limusa: Mexico, 1992. 